\title{
A hybrid MCDM framework combined with DEMATEL-based ANP to evaluate enterprise technological innovation capabilities assessment
}

\author{
Meng-Jong Kuan ${ }^{a}$ and Yee Ming Chen ${ }^{b^{*}}$
}

${ }^{a}$ Graduate Institute of Innovation and Project Management, Kainan University, Taiwan, R.O.C

${ }^{b}$ Innovation Center for Big Data and Digital Convergence, and Department of Industrial Engineering and Management, Yuan Ze University, Taoyuan, Taiwan, R.O.C

\section{CHRON I C L E}

Article history:

Received February 14, 2014

Accepted June 22, 2014

Available online

June 262014

Keywords:

Technological innovation

capability

DEMATEL

VIKOR

ANP

\begin{abstract}
A B S T R A C T
The efficient evaluation of technological innovation capabilities of enterprises is an important factor to enhance competitiveness. This paper aims to assess and to rank technological innovation evaluation criteria in order to provide a practical insight of systematic analysis by gathering the qualified experts' opinions combined with three methods of multi-criteria decision making approach. A framework is proposed and uses a novel hybrid multiple criteria decision-making (MCDM) model to address the dependence relationships of criteria with the aid of the Decision-Making Trial and Evaluation Laboratory (DEMATEL), analytical network process (ANP) and VIKOR (VlseKriterijumska Optimizacija I Kompromisno Resenje). The study reports that the interaction between criteria is essential and influences technological innovation capabilities; furthermore, this ranking development of technological innovation capabilities assessment is also one of key management tools for managements of other related high- tech enterprises. Managers can then judge the need to improve and determine which criteria provide the most effective direction towards improvement.
\end{abstract}

(C) 2014 Growing Science Ltd. All rights reserved.

\section{Introduction}

Technological innovation capabilities are the ability to create new technologies and to develop new products, processes or new industries in response to changing economic environment (Damanpour, 2010). The capabilities are required in order to adopt, to adapt and to modify technologies developed elsewhere, to introduce modifications and incremental innovations and eventually to generate totally new products and processes. Research has shown that innovative technological capability building is a key to technological and economic progress of enterprises throughout history (Armbruster et al., 2008). In the light of technological innovation capabilities, we need an effective multiple criteria decision-making (MCDM) analysis tools to assess the impact of organizational innovation and performance factors so that we could promote organizational innovation performance require (Coombs \& Bierly, 2006; Wang et al., 2008).

\footnotetext{
* Corresponding author.

E-mail address: chenyeeming@saturn.yzu.edu.tw (Y. M. Chen)

C 2014 Growing Science Ltd. All rights reserved doi: $10.5267 /$ j.ds1.2014.6.003
} 
The possible role of technological innovation has been described in creating sustained competitive advantages for organizations (Chen et al., 2011). Jung et al. (2010), however, pointed out that technological innovation capabilities depend on a wider and trans-functional integration capability. Technological innovation capabilities are as a whole set of an enterprise's characteristics that facilitate the enterprise's technological innovation strategies. The developments of capabilities are also rather important and closely related to their sustainability (Johannessen, 2003).

Despite the importance of technological innovation capabilities, the previous studies have not paid much attention to the importance of its assessment criteria and the cause and effect relationships among criteria. In these areas, technological innovation capabilities are regarded not only as one of the enterprises' solutions but as the method of effective measurement under the multi-dimensions of criteria (Eisenhardt \& Martin, 2000). Therefore, it is worth more attention. This study used the Decision Making Trial and Evaluation Laboratory (DEMATEL) technique to acquire the structure of the MCDM problems. The weights of each criterion from the structure are obtained by utilizing the Analytical Network Process (ANP).

The VIKOR technique will be leveraged for calculating compromise ranking and gap of the alternatives. In short, the framework of evaluation contains three main phases: (1) constructing the network relation map (NRM) among criteria by the DEMATEL technique, (2) calculating the weights of each criterion by the ANP based on the NRM, and (3) ranking or improving the priorities of alternatives of portfolios through the VIKOR(VlseKriterijumska Optimizacija I Kompromisno Resenje).

The rest of this paper is organized as follows: In section 2, the research motivation and related theoretical background is illustrated. Section 3 presents the structure of the framework of this study. Section 4 subsequently applies a proposed method in evaluating a case enterprise. Finally, conclusions are drawn in Section 5.

\section{Related works}

Technological innovation capabilities included knowledge capture, documentation, and sharing within a project team or organization. It has increasingly become a business process, supported by database technologies and activities aimed at the creation and sharing of knowledge (Jiménez \& Sanz, 2011). Appropriate technological innovation strategies are important to ensure that the alignment of the organizational process, culture, and the related information technology deployment produce effective knowledge creation, sharing, and utilization (Menguc \& Auh, 2010). Sarvary (1999) defined technological innovation as knowledge obtaining, knowledge refining, knowledge storing and knowledge sharing. Damanpour et al. (2006) noted that product life cycles are currently becoming shorter and emphasized that the way for an enterprise to win this battle is to cultivate core capabilities and to convert them into a sharp weapon. The capture of knowledge, the exploitation of existing knowledge, and the distribution of new knowledge are critical for long-term sustainable development.

Among the major technology innovation evaluation techniques, MCDM-based decision analysis approaches have been widely adopted. MCDM-based technology innovation evaluation framework for selecting the most suitable emerging technology and explore opportunities. The framework can be used in selecting technology for enhancing innovation competencies at enterprises. Then, the Decision Making Trial and Evaluation Laboratory (DEMATEL) will be used for configuring the structure of the decision framework. DEMATEL was first developed by American scientists in a Science and Human Affairs Program in the early 1970s (Gabus \& Fontela, 1973).

DEMATEL is based on graph theory, enabling us to analyze and solve problems visually. Through the analysis of visual relationship, all elements can be divided into a cause-effect group, which helps researchers understand the structural relationship between elements and plot a network relationship map. Therefore, DEMATEL is a mathematical computational method that can convert the relations 
between the cause and effect of criteria into a visual structural model. In addition, it can be used as an effective method to handle the inner dependences within a set of criteria. The main advantage of DEMATEL is that it involves indirect relations within a cause and effect model. The DEMATEL method is an effective procedure for analyzing structure and relationships between components; it can prioritize the criteria based on the type of relationships and severity of influences they have on one another. The criteria having a greater effect on one another are assumed to have a higher priority and are called cause criteria. In contrast, those that receive more influence from another are assumed to have lower priority and are called effect criteria. As any criterion may impact each other, this study used the DEMATEL technique to acquire the structure of the MCDM problems. The weights of each criterion from the structure are obtained by utilizing the ANP. It demonstrates that the quantitative technique of interdependences among various aspects and criteria can be effectively captured using the ANP technique and combined with DEMATEL, which is rarely applied in the literature. This study attempts to develop a hierarchical framework that is sufficiently general that it can be applied under various research settings.

The advantage of using a combination of ANP and DEMATEL is that it considers the hierarchical structure, including interdependence relationships in the condition of flexibly manages the fuzziness situation. With these advantages, the DEMATEL method is used to determine the cause and effect of criteria and to understand the hierarchical structure with interdependence relations; ANP is proposed for application in a hierarchical structure. Hence, using ANP and DEMATEL, subjectivity, uncertainty and interactivity can be supported expert subjective judgment problems involving complex hierarchical relationships among technological innovation capabilities evaluation aspects and criteria. This study provides an analytical approach for managerial decision making. It demonstrates that the quantitative technique of interdependences among various aspects and criteria can be effectively captured using the ANP technique and combined with DEMATEL.

Opricovic (1998) proposed the compromise ranking method (VIKOR) as one applicable technique to implement within MCDM. This method focuses on the multiple criteria optimization and compromise solution. Thus, selecting from a set of alternatives and ranking can be possible via the VIKOR method. The compromise solution is the closest one to the ideal solution and it shows that an agreement reached by mutual concessions (Kuan et al., 2012). The compromise-ranking method (VIKOR) is applied to determine the compromise solution and the solution is adoptable for decisionmakers in that it offers a maximum group utility of the majority, and a maximal regret of minimum individuals of the opponent. This model utilizes the DEMATEL and ANP processes in Sections 3.1 and 3.2 to get the weights of criteria with dependence and feedback and employs the VIKOR method to acquire the compromise solution.

\section{Research method}

Traditional MCDM approaches based on unrealistic assumptions on independencies between criteria cannot be feasible for many real business case studies. Moreover, the MCDM framework based solely on the ANP does not have an appropriate method of structuring a decision, so the authors propose a hybrid, MCDM technological innovation capabilities evaluation framework for selecting the most suitable emerging technology and explore opportunities. The evaluation measures are multiple and are frequently structured into the framework of this study (see Table 1), using both qualitative and quantitative assessment. The measures consist of 5 aspects and 17 criteria and they were determined from an extensive literature search. 
Table 1

Enterprises'technological innovation capabilities evaluation criteria

\begin{tabular}{|c|c|c|}
\hline Aspects & Criteria & Description \\
\hline \multirow{4}{*}{$\begin{array}{l}\text { Technological } \\
\text { innovation } \\
\text { capability input } \\
\text { (A) }\end{array}$} & \multicolumn{2}{|c|}{$\begin{array}{l}\text { Technological innovation investment capacity is the enterprise technology innovation project activities from a variety of resources, and its essence is } \\
\text { technology and knowledge resources into innovation. }\end{array}$} \\
\hline & $\begin{array}{l}\text { Knowledge resource } \\
\text { inputs(A1) }\end{array}$ & $\begin{array}{l}\text { Enterprise's ability is required to create organizational learning addresses the management of learning and education } \\
\text { mechanisms for organizational innovation. } \\
\text { Enterprise is able to drive knowledge of communication mechanism and ability to utilize knowledge in order to enhance } \\
\text { an organizational innovation. }\end{array}$ \\
\hline & $\begin{array}{l}\text { Material resources } \\
\text { invested(A2) }\end{array}$ & Enterprise's ability is required to appropriately acquire and allocate capital $\&$ technology. \\
\hline & $\begin{array}{l}\text { Human resource inputs } \\
\text { (A3) }\end{array}$ & Enterprise has an effective process to obtain the employees' participation in order to get an innovative idea. \\
\hline \multirow{4}{*}{$\begin{array}{l}\text { Learning ability } \\
\text { of technological } \\
\text { innovation (B) }\end{array}$} & \multicolumn{2}{|c|}{$\begin{array}{l}\text { Technical innovation is the ability to learn and min ing enterprises in order to develop the necessary knowledge and skills potential, through access to } \\
\text { knowledge, absorption, accumulation and transformation to improve the ability of enterprises to adapt to the environment. }\end{array}$} \\
\hline & $\begin{array}{l}\text { Knowledge acquisition } \\
\text { capability (B1) }\end{array}$ & $\begin{array}{l}\text { Enterprise is enable to acquire and exchange the external knowledge addresses the management of an external } \\
\text { information influencing organizational innovation in terms of competition, market, acquisition and the communication of } \\
\text { technology. }\end{array}$ \\
\hline & $\begin{array}{l}\text { Knowledge absorptive } \\
\text { capacity (B2) }\end{array}$ & $\begin{array}{l}\text { Enterprise is able to internal knowledge development addresses management of the development and exploration of } \\
\text { knowledge generated internally for organizational innovation. }\end{array}$ \\
\hline & $\begin{array}{l}\text { Knowledge sharing } \\
\text { capabilities (B3) }\end{array}$ & Mechanisms for sharing technological environmental knowledge across business boundaries \\
\hline \multirow{4}{*}{$\begin{array}{l}\text { Ability to } \\
\text { implement } \\
\text { technological } \\
\text { innovation }(\mathrm{C})\end{array}$} & \multicolumn{2}{|c|}{$\begin{array}{l}\text { Ability to implement technological innovation, including research and development capability and production capacity, and its essence is the knowledge } \\
\text { innovation, but also the key to the overall process of technological innovation value chain. }\end{array}$} \\
\hline & $\begin{array}{l}\text { R \& D capabilities } \\
\text { (C1) }\end{array}$ & $\begin{array}{l}\text { Enterprise is able to integrate all phases of R\&D process and to systematically connect to other functions e.g. } \\
\text { engineering, production, marketing. }\end{array}$ \\
\hline & $\begin{array}{l}\text { Production capacity } \\
\text { (C2) }\end{array}$ & $\begin{array}{l}\text { Enterprise is able to transform R\&D outputs into production and to acquire the innovation of an advanced manufacturing } \\
\text { technology/method. }\end{array}$ \\
\hline & $\begin{array}{l}\text { Risk control capability } \\
\text { (C3) }\end{array}$ & $\begin{array}{l}\text { Enterprise's capability involves in risk assessment, risk taking and responding to technological innovation change and } \\
\text { adopting. }\end{array}$ \\
\hline \multirow{4}{*}{$\begin{array}{l}\text { Ability to } \\
\text { achieve } \\
\text { technological } \\
\text { innovation (D) }\end{array}$} & \multicolumn{2}{|c|}{$\begin{array}{l}\text { Technical innovation is the ability to achieve sales of innovative products in the market knowledge and innovation in this market segment in the ability to } \\
\text { profit by technical trading, its essence is the application of knowledge, including marketing capacity and output capacity. }\end{array}$} \\
\hline & $\begin{array}{l}\text { Marketing capabilities } \\
\text { (D1) }\end{array}$ & $\begin{array}{l}\text { Enterprise awareness of customer environmental requirements and } \\
\text { Preferences. }\end{array}$ \\
\hline & $\begin{array}{l}\text { Throughput capabilities } \\
\text { (D2) }\end{array}$ & Firm is able to design a product structure, modularization and process compatibility. \\
\hline & $\begin{array}{l}\text { Brand impact } \\
\text { (D3) }\end{array}$ & $\begin{array}{l}\text { Brand impact including: the core brand, brand market power, brand loyalty, brand radiation, brand innovation, brand } \\
\text { vitality and brand culture and brand leadership. }\end{array}$ \\
\hline \multirow{6}{*}{$\begin{array}{l}\text { Technical } \\
\text { innovation } \\
\text { project } \\
\text { management } \\
\text { capabilities (E) }\end{array}$} & \multicolumn{2}{|c|}{$\begin{array}{l}\text { Technical innovation is an enterprise project management capabilities to discover and evaluate opportunities for innovation, innovation strategy, } \\
\text { innovative mechanisms, organization and management of technological innovation activities, project management capabilities. }\end{array}$} \\
\hline & $\begin{array}{l}\text { Innovation Strategy } \\
\text { (E1) }\end{array}$ & $\begin{array}{l}\text { Enterprise 's innovation roadmap provides a framework for future innovations in various key technological areas in order } \\
\text { to ensure that investment in technological innovation and research is linked to the business' drivers and market trends. }\end{array}$ \\
\hline & $\begin{array}{l}\text { Innovative mechanisms } \\
\text { (E2) }\end{array}$ & $\begin{array}{l}\text { Enterprise has mechanism for continuous improvement which addresses management of revision and improvement } \\
\text { projects that influence organizational innovation. }\end{array}$ \\
\hline & $\begin{array}{l}\text { Innovative Organization } \\
\text { (E3) }\end{array}$ & Enterprise has an ability to create a systematic idea leading to the new source of ideas. \\
\hline & $\begin{array}{l}\text { Project management } \\
\text { capacity } \\
\text { (E4) }\end{array}$ & Ability to build and develop project contacts and collaborate with other company, universities and R\&D centers. \\
\hline & $\begin{array}{l}\text { Innovation Project } \\
\text { Management } \\
\text { (E5) }\end{array}$ & $\begin{array}{l}\text { Enterprise is able to transform R\&D outputs into production and to acquire the innovation of an advanced manufacturing } \\
\text { technology/ method. }\end{array}$ \\
\hline
\end{tabular}

\subsection{Using DEMATEL to construct technological innovation capability evaluation framework}

According to existing literature, DEMATEL is very useful for visually structuring the cause-effect relationship of complex problems. The calculation of DEMATEL could be divided into five steps:

Step 1: To calculate the direct-influence matrix using scores. The experts are asked to indicate the direct effect that they believe factor $\mathrm{i}$ will have on factor $\mathrm{j}$. In the DEMATEL formulation, respondents indicate the degree of direct influence on a scale of $0,1,2,3$ and 4 , which represent "Complete no influence (0)", "Low influence (1)", "Medium influence (2)", "High influence (3)" and "Very high influence (4)" by experts, respectively.

Step 2: To normalize the direct-influence matrix. Based on the direct-influence of matrix, the normalized direct-relation matrix is acquired using Eq. (1) and Eq. (2).

$\tilde{\boldsymbol{D}}=\tilde{\boldsymbol{A}} / k$

$k=\max \left\{\max _{i} \sum_{j=1}^{n} h_{i j} \max _{j} \sum_{i=1}^{n} h_{i j}\right\} \quad, \quad i, j \in\{1,2, \ldots, n\}$ 
Step 3: To obtain the total-influence matrix. Once the normalized direct-influence matrix D is obtained, the total-influence matrix of NRM can be obtained by using Eq. (3), which denotes the identity matrix.

$$
\begin{aligned}
& \tilde{\boldsymbol{T}}=\tilde{\boldsymbol{D}}+\tilde{\boldsymbol{D}}^{2}+\tilde{\boldsymbol{D}}^{3}+\ldots+\tilde{\boldsymbol{D}}^{k}=\tilde{\boldsymbol{D}}\left(\boldsymbol{I}+\tilde{\boldsymbol{D}}+\tilde{\boldsymbol{D}}^{2}+\ldots+\tilde{\boldsymbol{D}}^{k-1}\right)\left[(\boldsymbol{I}-\tilde{\boldsymbol{D}})(\boldsymbol{I}-\tilde{\boldsymbol{D}})^{-1}\right]=\tilde{\boldsymbol{D}}\left(\boldsymbol{I}-\tilde{\boldsymbol{D}}^{h}\right)(\boldsymbol{I}-\tilde{\boldsymbol{D}})^{-1} \\
& \tilde{\boldsymbol{T}}=\tilde{\boldsymbol{D}}(\boldsymbol{I}-\tilde{\boldsymbol{D}})^{-1}, \text { when } k \rightarrow \infty, \tilde{\boldsymbol{D}}^{k}=[0]_{n \times n}
\end{aligned}
$$

where $\tilde{\boldsymbol{D}}=\left[\tilde{d}_{i j}\right]_{n \times n}=\left[\left(d_{i j}^{l}, d_{i j}^{m}, d_{i j}^{h}\right)\right]_{n \times n}, 0 \leq \tilde{d}_{i j}<1,0<\sum_{j=1}^{n} d_{i j}^{h} \leq 1,0<\sum_{i=1}^{n} d_{i j}^{h} \leq 1$. If at least one row or column of summation is equal to 1 (but not all) in $\sum_{j=1}^{n} d_{i j}^{h}$ and $\sum_{i=1}^{n} d_{i j}^{h}$, then it can be guaranteed that $\lim _{k \rightarrow \infty} \boldsymbol{D}^{k}=[0]_{n \times n}$. And $\tilde{\boldsymbol{T}}=\left[\tilde{t}_{i j}\right]$ can be attained.

Step 4: To analyze the results. In this stage, the sum of rows $\sum_{j=1}^{n} \tilde{t}_{i j}=\tilde{t}_{i}$ and the sum of columns $\sum_{i=1}^{n} \tilde{t}_{i=1} \tilde{t}_{j}$ are separately expressed as vector $\boldsymbol{r}=\left(\tilde{r}_{1}, \cdots, \tilde{r}_{i}, \cdots, \tilde{r}_{n}\right)^{\prime}$ and vector $\boldsymbol{c}=\left(\tilde{c}_{1}, \cdots, \tilde{c}_{i}, \cdots, \tilde{c}_{n}\right)^{\prime}$ by using Eq. (4), Eq. (5), and Eq. (6).

Let $i=j$ and $i, j \in\{1,2, \ldots, n\}$; the horizontal axis vector $(\tilde{\boldsymbol{r}}+\tilde{\boldsymbol{c}})$ is then created by adding $\tilde{\boldsymbol{r}}$ to $\tilde{\boldsymbol{c}}$, which illustrates the importance of the criterion. Similarly, the vertical axis vector $(\tilde{\boldsymbol{r}}-\tilde{\boldsymbol{c}})$ is constructed by deducting $\tilde{\boldsymbol{r}}$ from $\tilde{\boldsymbol{c}}$, which may separate criteria and group them into a cause group and an effect group. In general, when $(\tilde{\boldsymbol{r}}-\tilde{\boldsymbol{c}})$ is positive, the criterion is part of the cause group. In contrast, if vector $(\tilde{\boldsymbol{r}}-\tilde{\boldsymbol{c}})$ is negative, the criterion is part of the effect group. Therefore, the causal graph can be achieved by mapping the dataset of vectors $(\tilde{\boldsymbol{r}}+\tilde{\boldsymbol{c}}, \tilde{\boldsymbol{r}}-\tilde{\boldsymbol{c}})$, providing a valuable approach to decision making.

$$
\begin{aligned}
& \tilde{\boldsymbol{T}}=\left[\tilde{t}_{i j}\right]_{n \times n}, i, j=1,2, \ldots, n \\
& \tilde{\boldsymbol{r}}=\left[\sum_{j=1}^{n} \tilde{t}_{i j}\right]_{n \times 1}=\left[\tilde{t}_{i \cdot}\right]_{n \times 1}=\left(\tilde{r}_{1}, \ldots, \tilde{r}_{i}, \ldots, \tilde{r}_{n}\right)^{\prime} \\
& \tilde{\boldsymbol{c}}=\left[\sum_{i=1}^{n} \tilde{t}_{i j}\right]_{1 \times n}^{\prime}=\left[\tilde{t}_{. j}\right]_{n \times 1}=\left(\tilde{c}_{1}, \ldots, \tilde{c}_{j}, \ldots, \tilde{c}_{n}\right)^{\prime}
\end{aligned}
$$

where vector $\tilde{\boldsymbol{r}}$ and vector $\tilde{\boldsymbol{c}}$ express the sum of the rows and the sum of the columns from totalinfluence matrix $\tilde{T}=\left[\tilde{t}_{i j}\right]_{n \times n}$, respectively, and the use of superscript denotes transpose.

\subsection{Using DANP method to calculate the influential weights of criteria}

Saaty (2004) proposed ANP by extending the Analytic Hierarchy Process (AHP). The difference of ANP from AHP is that it sees the criteria independent, while AHP considers the dependence and feedback relation in each criterion. In other words, ANP is a general form of Analytic Hierarchy Process. It also means that AHP is a special case of ANP. In fact, the dimensions formed by the criteria have not only the influence in the same level, but also the influences in different levels. In reality, it is not a linear bottom up and breakdown hierarchy, but is more like a network. The purpose of ANP is to predict the internal relationship between criteria, goals, and alternatives. Through an evaluation scale doing the pair-wise comparison, we can obtain the weight of cluster and every element after influencing each other. In this study, we use the method that combines DEMATEL technique and basic concept of ANP which is called DANP (DEMATEL-based ANP). DANP uses DEMATEL technique to confirm the degree of influence between each cluster. Furthermore, it uses the total relationship matrix $\mathrm{T}$ obtained from DEMATEL that contains "dynamic influential 
relationship weights". It then makes use of the total relationship matrix $\mathrm{T}$ unto the super-matrix in ANP to recognize the relation and importance which influence the management and development of a project team; thus meeting the requirement of our research topic in the real world. The following are the DANP operation steps:

Step 1: Use DEMATEL method to establish evaluation index system of influential relationship, which is the system structure model.

Step 2: Establish Unweighted Super-matrix. Based on the influence matrix $\boldsymbol{T}$, each criterion $t_{i j}$ of influence matrix $\boldsymbol{T}$ can show network information on how the degree of criterion $i$ affects criterion $j$ ; and thus the network relation map (NRM) can be obtained. The influence matrix $\boldsymbol{T}$ can be divided into $\boldsymbol{T}_{D}$ based on dimensions, and $\boldsymbol{T}_{C}$ based on criteria.

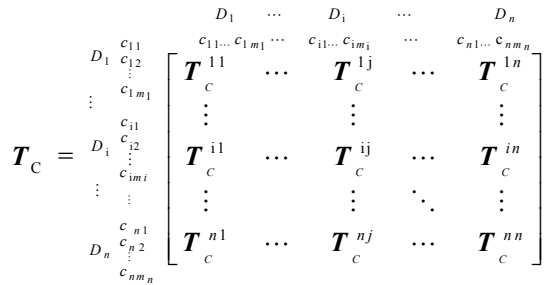

Then, to normalize $\boldsymbol{T}_{C}$ with the total degree of effect and to obtain $\boldsymbol{T}_{C}^{\alpha}$ as shown in Eq. (8):

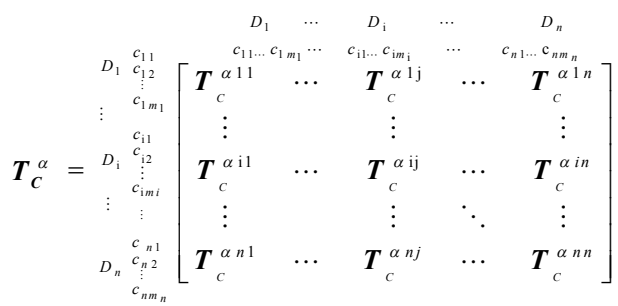

The method of normalization that can be obtained $\boldsymbol{T}_{c}^{\alpha 11}$ is shown in Eqs (9) and (10), this can be repeated to be obtain $\boldsymbol{T}_{c}^{\alpha n n}$

$d_{i}^{11}=\sum_{j=1}^{m_{1}} t_{C^{i j}}^{11}, i=1,2, \ldots, m_{1}$

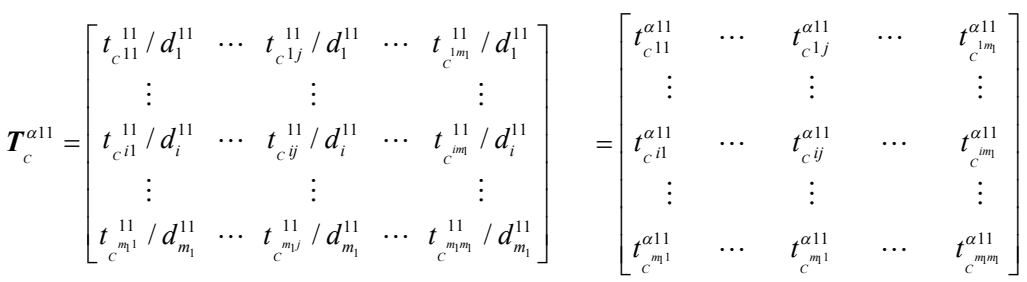

After this, the total effect matrix is normalized into a supermatrix by dimensions according to the dependent relationship within the group; this results to obtaining the unweighted supermatrix as shown in Eq. (11).

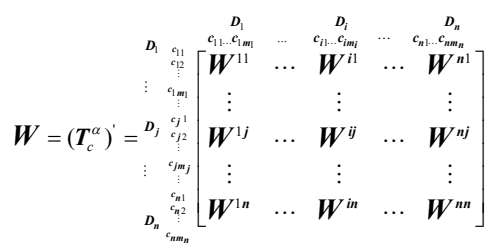


Furthermore, matrices $\boldsymbol{W}^{11}$ can be obtained by Eq. (12). If a blank space or 0 appears in the matrix, then the group or criterion is independent. In the same way, the matrix $\boldsymbol{W}^{n n}$ can be obtained.

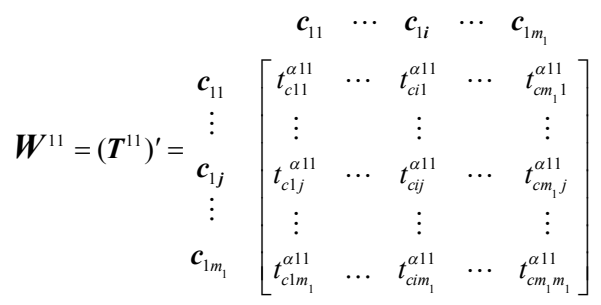

Step 3: Obtain the Weighted Supermatrix by deriving the matrix of the total effect of dimensions using Eq. (13).

$$
\boldsymbol{T}_{D}=\left[\begin{array}{ccccc}
t_{D}^{11} & \cdots & t_{D}^{1 j} & \cdots & t_{D}^{1 n} \\
\vdots & & \vdots & & \vdots \\
t_{D}^{i 1} & \cdots & t_{D}^{i j} & \cdots & t_{D}^{i n} \\
\vdots & & \vdots & & \vdots \\
t_{D}^{n 1} & \cdots & t_{D}^{n j} & \cdots & t_{D}^{n n}
\end{array}\right] \sum_{j=1}^{n} t_{D}^{i j}, i=1,2, \ldots, n
$$

Then, $\boldsymbol{T}_{D}$ is normalized to obtain $\boldsymbol{T}_{D}^{\alpha}$, as shown in Eq. (14).

$\boldsymbol{T}_{D}^{\alpha}=\left[\begin{array}{ccccc}t_{D}^{11} / d_{1} & \cdots & t_{D}^{1 j} / d_{1} & \cdots & t_{D}^{1 n} / d_{1} \\ \vdots & & \vdots & & \vdots \\ t_{D}^{i 1} / d_{2} & \cdots & t_{D}^{i j} / d_{2} & \cdots & t_{D}^{i n} / d_{2} \\ \vdots & & \vdots & & \vdots \\ t_{D}^{n 1} / d_{n} & \cdots & t_{D}^{n j} / d_{n} & \cdots & t_{D}^{n n} / d_{n}\end{array}\right]=\left[\begin{array}{ccccc}t_{D}^{\alpha 11} & \cdots & t_{D}^{\alpha 1 j} & \cdots & t_{D}^{\alpha 1 n} \\ \vdots & & \vdots & & \vdots \\ t_{D}^{\alpha i 1} & \cdots & t_{D}^{\alpha i j} & \cdots & t_{D}^{\alpha i n} \\ \vdots & & \vdots & & \vdots \\ t_{D}^{\alpha n 1} & \cdots & t_{D}^{\alpha n j} & \cdots & t_{D}^{\alpha n n}\end{array}\right]$

Then, the normalized $\boldsymbol{T}_{D}^{\alpha}$ is transformed into the Unweighted Supermatrix $\boldsymbol{W}$ to obtain the Weighted Supermatrix $\boldsymbol{W}^{\alpha}$, as shown in Eq. (15).

$\boldsymbol{W}^{\alpha}=\boldsymbol{T}_{D}^{\alpha} \boldsymbol{W}=\left[\begin{array}{ccccc}t_{D}^{\alpha 11} \times \boldsymbol{W}^{11} & \cdots & t_{D}^{\alpha i 1} \times \boldsymbol{W}^{i 1} & \cdots & t_{D}^{\alpha 11} \times \boldsymbol{W}^{n 1} \\ \vdots & & \vdots & & \vdots \\ t_{D}^{\alpha 1 j} \times \boldsymbol{W}^{1 j} & \cdots & t_{D}^{\alpha i j} \times \boldsymbol{W}^{i j} & \cdots & t_{D}^{\alpha n j} \times \boldsymbol{W}^{n j} \\ \vdots & & \vdots & & \vdots \\ t_{D}^{\alpha 1 n} \times \boldsymbol{W}^{1 n} & \cdots & t_{D}^{\alpha i n} \times \boldsymbol{W}^{i n} & \cdots & t_{D}^{\alpha n n} \times \boldsymbol{W}^{n n}\end{array}\right]$

Step 4: Obtain the Limit Supermatrix by DANP. Let the Weighted Spuermatrix $\boldsymbol{W}^{\alpha}$ multiply itself multiple times to obtain the Limit Supermatrix. Then, the DANP weights of each criterion can be obtained by $\lim _{z \rightarrow \infty}\left(\boldsymbol{W}^{\alpha}\right)^{z}$, where $z$ represents any number for power (Yang et al., 2008).

\subsection{Using VIKOR to find the best alternative}

VIKOR a method proposed by Opricovic, is a method of decision making on compromise solution programming. In this research, it uses a compromise concept to sort the multiple alternatives to see how close the project is to Positive-ideal solution (setting the aspiration level). The closer the alternative is to the ideal solution (aspiration level), the better. On the contrary, the closer it is to the Negative-ideal solution, the worst. VIKOR could be divided into 3 steps: 
Step 1: To confirm the ideal solution (aspiration level) and negative ideal solution (the worst level), and to confirm the best and worst value, which can be could obtained from Eqs. (7) and (8). $f_{j}^{*}$ is the aspiration level of criterion $j$, and $f_{j}^{-}$is the worst value of criterion $j$. If every criterion in the project gets the aspiration level, it means that the project gets best performance in every criterion and approaches the aspiration level. Eq. (16) and Eq. (17) are then used to obtain the results.

$f_{j}^{*}=\max _{k} f_{k j}, \quad j=1,2, \ldots, n$ (traditional approach) or as method in this research: setting the aspiration levels vector.

$\boldsymbol{f}^{*}=\left(f_{1}^{*}, \ldots, f_{j}^{*}, \ldots, f_{n}^{*}\right)$

$f_{j}^{-}=\min _{k} f_{k j}, j=1,2, \ldots, n$ (traditional approach) or as method in this research: setting the worst values vector.

$\boldsymbol{f}^{-}=\left(f_{1}^{-}, \ldots, f_{j}^{-}, \ldots, f_{n}^{-}\right)$

Development of the VIKOR method begins with the following form of the $L_{p \_}$metric:

$L_{k}^{p}=\left\{\sum_{j=1}^{n}\left[w_{j}\left(f_{j}^{*}-f_{k j} \mid\right) /\left(\left|f_{j}^{*}-f_{j}^{-}\right|\right)\right]^{p}\right\}^{1 / p}$

where $1 \leq p \leq \infty ; k=1,2, \ldots, m$ and the influential weights $w_{j}$ is derived from the DANP. VIKOR method is used to formulate the ranking and gap measure, $L_{k}^{p=1}\left(\right.$ as $\left.S_{k}\right)$ and $L_{k}^{p=\infty}\left(\right.$ as $\left.Q_{k}\right)$.

$$
\begin{aligned}
& S_{k}=L_{k}^{p=1}=\sum_{j=1}^{n}\left[w_{j}\left(\left|f_{j}^{*}-f_{k j}\right|\right) /\left(\left|f_{j}^{*}-f_{j}^{-}\right|\right)\right] \\
& Q_{k}=L_{k}^{p=\infty}=\max _{j}\left\{\left(\left|f_{j}^{*}-f_{k j}\right|\right) /\left(\left|f_{j}^{*}-f_{j}^{-}\right|\right) \mid j=1,2, \ldots, n\right\}
\end{aligned}
$$

Step 2: Calculate the mean of the group utility $S_{k}$ (which represents the integrated average gap for all criteria) and maximal regret $Q_{k}$ (which represents the maximal gap in $k$ alternative of special criterion for improvement priority). Where $w_{j}$ represents the influential weights of the criteria from DANP.

$r_{k j}=\left(\left|f_{j}^{*}-f_{k j}\right|\right) /\left(\left|f_{j}^{*}-f_{j}^{-}\right|\right)$

which represents the normalized gap (the normalized ratios of distance to the aspired level) of $\mathrm{k}$ alternative in j criterion. These values can be computed by Eq. (18) and Eq. (19), respectively.

$$
\begin{aligned}
& S_{k}=\sum_{j=1}^{n} w_{j} r_{k j}=\sum_{j=1}^{n} w_{j}\left(\left|f_{j}^{*}-f_{k j}\right|\right) /\left(\left|f_{j}^{*}-f_{j}^{-}\right|\right) \\
& Q_{k}=\max _{j}\left\{r_{k j} \mid j=1,2, \ldots, n\right\}
\end{aligned}
$$

Step 3: Obtain the comprehensive indicator and sort out the results. The values can be computed by Eq. (24).

$$
R_{k}=v\left(S_{k}-S^{*}\right) /\left(S^{-}-S^{*}\right)+(1-v)\left(Q_{k}-Q^{*}\right) /\left(Q^{-}-Q^{*}\right)
$$

Eq. (20) can be re-written as $R_{k}=v S_{k}+(1-v) Q_{k}$, when $S^{*}=0$ and $Q^{*}=0$ (i.e., all criteria have achieved the aspired level) and $S^{-}=1$ and $Q^{-}=1$ (i.e., the worst situation). 


\section{Empirical evaluation of case enterprises}

This section aims to evaluate the criteria associated with technological innovation capability for a case study of an enterprise. The proposed case study continues to improve production processes and faces challenges concerning how to manage the environmental practices in KMC in the competitive environment. In addition, the case enterprise has to sustain reform technological innovation capability in the R\&D sector in order to face high-tech market competition and social responsibility. The expert team is composed of three professors, one vice president and six management professions with extensive experience consulting in this study. The DEMATEL method introduced in Section 3.1 will be utilized in the decision problem structure. First, the direct-influence matrix A for criteria was presented (see Table 1). Then, the normalized direct-influence matrix $\mathrm{S}$ for criteria can be calculated by Eq. (10). Third, the total direct-influence matrix $\mathrm{T}$ for criteria/dimensions was derived based on Eq. (14). Finally, the NRM was constructed by the $r$ and $d$ in the total direct-influence matrix $\mathbf{T}$ for each criterion, respectively. (see Table 2) and for each aspect(see Table 3) which shown in Fig. 1.

Table 1

The initial influence matrix A for criteria

\begin{tabular}{|c|c|c|c|c|c|c|c|c|c|c|c|c|c|c|c|c|c|}
\hline$A$ & A1 & $\mathrm{A} 2$ & $\mathrm{~A} 3$ & B1 & B2 & B3 & $\mathrm{C} 1$ & $\mathrm{C} 2$ & $\mathrm{C} 3$ & D1 & D2 & D3 & E1 & E2 & E3 & E4 & E5 \\
\hline$\overline{\mathrm{A} 1}$ & 0.0 & 1.5 & 0.8 & 3.8 & 2.8 & 3.3 & 3.3 & 2.5 & 2.8 & 2.8 & 3.3 & 3.0 & 1.8 & 1.5 & 1.3 & 1.5 & 1.8 \\
\hline A2 & 3.8 & 0.0 & 3.5 & 3.0 & 3.3 & 2.8 & 3.3 & 3.5 & 3.0 & 3.0 & 3.3 & 2.8 & 2.0 & 2.0 & 2.0 & 1.8 & 2.0 \\
\hline A3 & 3.3 & 1.3 & 0.0 & 3.0 & 3.5 & 3.5 & 2.8 & 3.3 & 3.5 & 3.0 & 3.3 & 3.8 & 2.3 & 2.0 & 1.8 & 1.5 & 2.0 \\
\hline $\mathrm{B} 1$ & 2.3 & 2.0 & 2.0 & 0.0 & 3.5 & 1.3 & 3.0 & 2.8 & 3.3 & 3.0 & 2.8 & 3.0 & 2.0 & 2.3 & 1.5 & 2.0 & 1.8 \\
\hline B2 & 1.3 & 2.3 & 2.3 & 1.0 & 0.0 & 1.3 & 3.3 & 3.8 & 3.0 & 3.3 & 3.3 & 2.5 & 1.5 & 2.0 & 2.0 & 1.3 & 2.0 \\
\hline B3 & 1.5 & 2.0 & 2.3 & 3.5 & 3.8 & 0.0 & 3.5 & 3.3 & 2.8 & 3.0 & 3.3 & 3.0 & 2.0 & 2.0 & 1.0 & 2.5 & 2.0 \\
\hline$\overline{\mathrm{C} 1}$ & 2.3 & 2.3 & 1.8 & 2.0 & 2.5 & 2.0 & 0.0 & 3.0 & 1.0 & 3.0 & 3.3 & 3.3 & 2.0 & 1.8 & 1.8 & 2.3 & 2.0 \\
\hline $\mathrm{C} 2$ & 1.5 & 2.3 & 2.3 & 1.8 & 2.3 & 2.3 & 1.0 & 0.0 & 1.5 & 2.8 & 3.8 & 2.8 & 2.0 & 1.0 & 1.8 & 2.5 & 2.0 \\
\hline C3 & 1.5 & 1.5 & 2.3 & 2.0 & 1.5 & 1.8 & 3.0 & 3.8 & 0.0 & 3.8 & 3.0 & 3.3 & 1.8 & 2.0 & 1.0 & 1.5 & 1.8 \\
\hline D1 & 1.5 & 2.0 & 1.5 & 1.8 & 2.3 & 1.5 & 1.8 & 1.3 & 1.8 & 0.0 & 3.3 & 1.0 & 1.3 & 2.0 & 1.3 & 1.8 & 1.8 \\
\hline D2 & 1.8 & 2.5 & 1.5 & 1.0 & 2.3 & 1.8 & 1.8 & 2.5 & 1.5 & 0.8 & 0.0 & 1.5 & 1.3 & 1.8 & 1.0 & 2.0 & 2.3 \\
\hline D3 & 1.5 & 2.0 & 2.3 & 1.8 & 1.0 & 1.8 & 1.3 & 1.3 & 1.3 & 3.0 & 3.8 & 0.0 & 1.8 & 1.5 & 1.5 & 1.8 & 1.8 \\
\hline$\overline{\mathrm{E} 1}$ & 3.3 & 3.0 & 3.3 & 3.0 & 3.0 & 3.0 & 3.0 & 3.3 & 3.0 & 2.8 & 2.5 & 3.0 & 0.0 & 3.3 & 3.8 & 3.3 & 3.5 \\
\hline E2 & 3.3 & 3.3 & 3.3 & 3.3 & 3.0 & 3.3 & 3.5 & 2.5 & 3.0 & 3.5 & 2.8 & 2.5 & 1.3 & 0.0 & 1.5 & 3.5 & 2.5 \\
\hline E3 & 3.0 & 3.5 & 3.0 & 2.8 & 3.0 & 2.5 & 2.8 & 2.8 & 2.8 & 2.8 & 2.5 & 2.5 & 0.8 & 3.5 & 0.0 & 3.8 & 3.3 \\
\hline E4 & 2.8 & 3.0 & 2.8 & 3.3 & 2.8 & 3.3 & 3.0 & 3.3 & 2.8 & 3.0 & 3.3 & 3.0 & 1.3 & 1.3 & 1.5 & 0.0 & 0.8 \\
\hline E5 & 3.3 & 3.5 & 3.3 & 3.5 & 3.0 & 3.0 & 3.3 & 3.3 & 3.0 & 3.0 & 3.3 & 3.0 & 1.5 & 1.8 & 1.5 & 3.5 & 0.0 \\
\hline
\end{tabular}

Table 2

The total-influence matrix $\mathbf{T}$ for the technological innovation in the respective criterions

\begin{tabular}{lcccc}
\hline T & $\mathrm{r}$ & $\mathrm{d}$ & $\mathrm{r}+\mathrm{d}$ & $\mathrm{r}-\mathrm{d}$ \\
\hline Knowledge resource inputs A1 & 2.9152 & 2.9351 & 5.8503 & -0.0199 \\
Material resources invested A2 & 3.5233 & 2.9908 & 6.5141 & 0.5325 \\
Human resource inputs A3 & 3.4007 & 2.9724 & 6.3731 & 0.4283 \\
\hline Knowledge acquisition capability B1 & 3.0126 & 3.1387 & 6.1513 & -0.1262 \\
Knowledge absorptive capacity B2 & 2.8151 & 3.4172 & 6.2323 & -0.6022 \\
Knowledge sharing capabilitiesB3 & 3.2345 & 2.9921 & 6.2266 & 0.2424 \\
\hline R \& D capabilities C1 & 2.8498 & 3.3936 & 6.2434 & -0.5439 \\
Production capacity C2 & 2.6482 & 3.6237 & 6.2719 & -0.9755 \\
Risk control capability C3 & 2.7562 & 3.1232 & 5.8794 & -0.367 \\
\hline Marketing capabilities D1 & 2.2254 & 3.6588 & 5.8841 & -1.4334 \\
Throughput capabilities D2 & 2.2176 & 4.0358 & 6.2534 & -1.8182 \\
Brand impact D3 & 2.3265 & 3.4648 & 5.7913 & -1.1383 \\
\hline Innovation StrategyE1 & 3.99 & 2.17 & 6.16 & 1.82 \\
Innovative mechanismsE2 & 3.63 & 2.51 & 6.14 & 1.12 \\
Innovative OrganizationE3 & 3.6 & 2.08 & 5.68 & 1.52 \\
Project management capacityE4 & 3.2 & 2.84 & 6.04 & 0.36 \\
Project management capabilities E5 & 3.66 & 2.64 & 6.3 & 1.02 \\
\hline
\end{tabular}


Table 3

The total-influence matrix $\mathbf{T}$ for aspects

\begin{tabular}{lcccc}
\hline T & $\mathrm{r}$ & $\mathrm{d}$ & $\mathrm{r}+\mathrm{d}$ & $\mathrm{r}-\mathrm{d}$ \\
\hline Technological innovation capability input A & 0.991556 & 0.845333 & 1.836889 & 0.146222 \\
Learning ability of technological innovation B & 0.912667 & 0.913333 & 1.826 & -0.00067 \\
Ability to implement technological innovation C & 0.827111 & 0.968667 & 1.795778 & -0.14156 \\
Ability to achieve technological innovation D & 0.676444 & 1.069778 & 1.746222 & -0.39333 \\
Technical innovation project management capabilities E & 1.094933 & 0.7056 & 1.800533 & 0.389333 \\
\hline
\end{tabular}

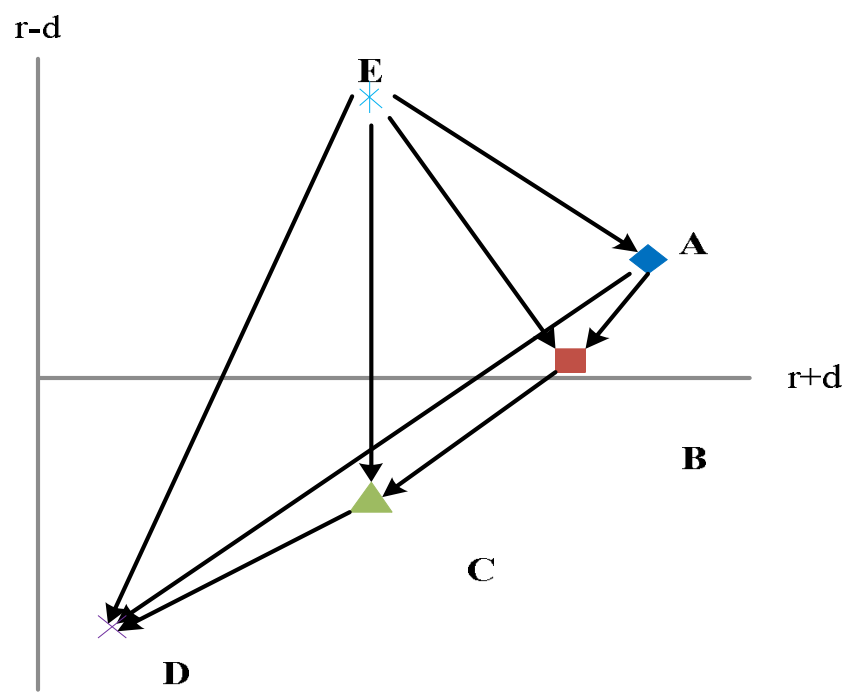

Fig. 1. The impact NRM of technological innovation capability evaluation

The VIKOR technique was applied for compromise ranking after the weights of determinants was calculated by ANP in Section 3.3. The results (in Fig. 2.) of VIKOR evaluation value indicated that case enterprise had the best technological innovation capability: throughput capabilities (D2) performance (the bigger the value is, the better it is). In contrast, innovation strategy (E1) had the worst technological innovation capability performance.

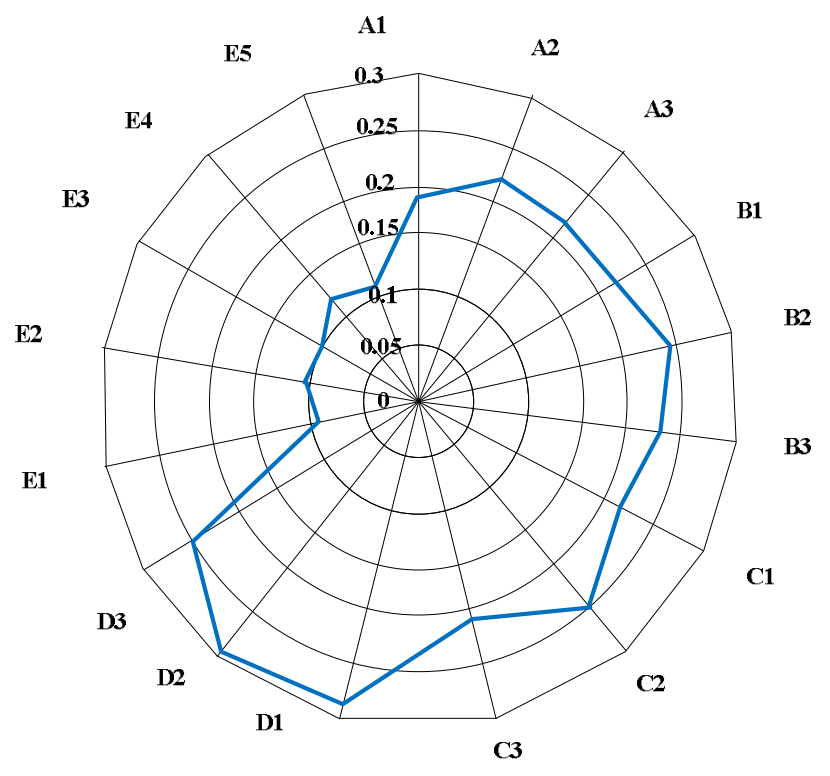

Fig. 2. Performance values of 17 criteria for case enterprise 
Technological innovation has become a key factor for the survival and development of enterprises. The technological innovation capabilities can be used to evaluate the performances and thus provide a mechanism to monitor and establish a measurement platform for the case enterprise. In particular, the evaluation framework can provide managers and researchers with a better understanding of the differences in activity needs and of specific management interventions that would improve the likelihood of excellent and useful research through the examination of the five aspects and seventeen criteria. These aspects and criteria serve as bridging mechanisms and are helpful in technological innovation capability evaluation.

\section{Conclusions}

There are different approaches to evaluate the technological innovation capabilities of enterprises, including the performance ranking. For this paper, a MCDM approach by the integration methods of DEMATEL, ANP, and VIKOR were proposed to develop the evaluation of technological innovation capabilities framework and rank the selected the case enterprise. This evaluation framework will be a useful solution to assist the management in the self-assessment that can indicate the most important criteria which are needed to be improved. It also enables the third independent parties e.g. auditing or consulting firms to apply framework as a systematic tool in their auditions or consultations because it can render the better solution. Research in the future could take more objective information on the applicability of the proposed evaluation framework, thus proving the practicality of the evaluation procedure proposed in this study.

\section{References}

Armbruster, H., Bikfalvi, A., Kinkel, S., \& Lay, G. (2008). Organizational innovation: The challenge of measuring non-technical innovation in large-scale surveys. Technovation, 28(10), 644-657.

Chen, Y., \& Chen, M. (2011). Social network analysis aided product development project management: IC Substrates case study. Management Science Letters, 1(2), 107-114.

Coombs, J. E., \& Bierly, P. E. (2006). Measuring technological capability and performance. $R \& D$ Management, 36(4), 421-438.

Damanpour, F. J. (2010). An integration of research findings of effects of firm size and market competition on product and process innovations. British Journal of Management, 21(4), 9961010.

Damanpour, F., \& Daniel Wischnevsky, J. (2006). Research on innovation in organizations: Distinguishing innovation-generating from innovation-adopting organizations. Journal of Engineering and Technology Management, 23(4), 269-291.

Eisenhardt, K. M., \& Martin, J. A. (2000). Dynamic capabilities: What are they? Strategic Management Journal, 21(10-11), 1105-1121.

Fontela, E., \& Gabus, A. (1976). The DEMATEL observer, DEMATEL 1976 report. Switzerland Geneva: Battelle Geneva Research Center.

Gabus, A., \& Fontela, E. (1973). Perceptions of the world problematique: Communication procedure, Communicating with those bearing collective responsibility (DEMATEL Report No. 1). Geneva, Switzerland: Battelle Geneva Research Centre.

Jiménez, J. D., \& Sanz Valle, R. (2011). Innovation, organizational learning and performance. Journal of Business Research, 64, 408-417.

Kuan, M. J., Hsiang, C. C., \& Tzeng, G. H. (2011). Probing the innovative quality system structure model for NPD Process based on combining DANP with MCDM model. International Journal of Innovative Computing, Information and Control, 8( 8), 5745 5762.

Leung, L. C., Hui, Y. V., \& Zheng, M. (2003). Analysis of compatibility between interdependent matrices in ANP. Journal of the Operational Research Society,54(7), 758-768.

Menguc, B., \& Auh, S. (2010). Development and return on execution of product innovation capabilities: The role of organizational structure. Industrial marketing management, 39(5), 820831. 
Opricovic, S. (1998). Multicriteria optimization of civil engineering systems. Faculty of Civil Engineering, Belgrade, 2(1), 5-21.

Johannessen, J. A., \& Olsen, B. (2003). Knowledge management and sustainable competitive advantages: The impact of dynamic contextual training. International Journal of Information Management, 23(4), 277-289.

Jung, U., \& Seo, D. W. (2010). An ANP approach for R\&D project evaluation based on interdependencies between research objectives and evaluation criteria.Decision Support Systems, 49(3), 335-342.

Saaty, T.L. (2004). The analytic network process: Dependence and feedback in decision making (Part 1): Theory and validation examples. In The 17th international conference on multiple criteria decesion making, August 6- 11, 2004. Whistler, British Columbia, Canada: The Whistler Conference Centre.

Sarvary, M. (1999). Knowledge management and competition in the consulting industry. California Management Review, 41 (2), 95-106.

Wang, C. H., Lu, I. Y., \& Chen, C. B. (2008). Evaluating firm technological innovation capability under uncertainty. Technovation, 28(6), 349-363.

Yang, Y. P. O., Shieh, H. M., Leu, J. D., \& Tzeng, G. H. (2008). A novel hybrid MCDM model combined with DEMATEL and ANP with applications. International Journal of Operations Research, 5(3), 160-168. 